\title{
Correction to: All-Trans Retinoic Acid Ameliorates the Early Experimental Cerebral Ischemia-Reperfusion Injury in Rats by Inhibiting the Loss of the Blood-Brain Barrier via the JNK/P38MAPK Signaling Pathway
}

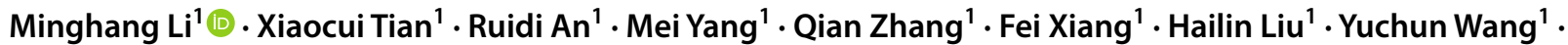
Lu Xu' ${ }^{2} \cdot$ Zhi Dong $^{1}$

Published online: 20 June 2018

๑) Springer Science+Business Media, LLC, part of Springer Nature 2018

\section{Correction to: Neurochemical Research (2018) 43:1283-1296 https://doi.org/10.1007/s11064-018-2545-4}

The original version of this article unfortunately contained a mistake. The affiliation of the author $\mathrm{Lu} \mathrm{Xu}$ has been submitted and published incorrectly and has been corrected with the erratum.

The original article can be found online at https://doi.org/10.1007/ s11064-018-2545-4.

$\mathrm{Lu} \mathrm{Xu}$

xulu8792@163.com

$\triangle$ Zhi Dong

dongzhi5536@163.com

1 Chongqing Key Laboratory of Biochemistry and Molecular Pharmacology, College of Pharmacy, Chongqing Medical University, District of Yuzhong, Chongqing 400016, China

2 School of Pharmacy, Chongqing Medical and Pharmaceutical College, Chongqing, China 